\title{
МИНЕРАЛЫ ЭЛЕМЕНТОВ ПЛАТИНОВОЙ ГРУППЫ В РАЗРЕЗЕ ЮЖНОГО РИФА ЗАПАДНО-ПАНСКОГО МАССИВА
}

\author{
Чернявский А.В. ${ }^{1}$, Грошев Н.Ю. ${ }^{1}$, Корчагин А.У. ${ }^{2}$, Шиловских В.В. ${ }^{3}$ \\ ${ }^{1}$ Геологический институт КНЦ РАН, Anamumbl, nikolaygroshev@gmail.com \\ ${ }^{2} \mathrm{OAO} «$ «ана», Апатиты \\ ${ }^{3}$ РЦ «Геомодель», СПбГУ, Санкт-Петербург
}

\section{Введение}

В Южном платинометальном рифе Западно-Панского массива Федорово-Панского расслоенного комплекса (ФПРК) ранее было установлено 29 минералов элементов платиновой группы (ЭПГ) и золота. Оруденение рифа является переотложенным и характеризуется резким преобладанием палладия над платиной (Pd/Pt 10). Минералы платиновых металлов (МПМ) представлены преимущественно куперитом-брэггитом и высоцкитом [2]. Проведенное нами исследование геохимических вариаций и минерального состава платинометального оруденения в скважине BG-S-30 (рис. 1, а) позволило выделить три минеральные ассоциации МПМ, сменяющие друг друга в разрезе рифа: сульфидную (тип 1), арсенидно-сульфидно-теллуридную (тип 2) и антимонидно-арсениднотеллуридную (тип 3). Сравнение с оруденением классического J-М рифа комплекса Стиллуотер подтвердило переотложенный характер платинометальной минерализации в Южном рифе, предполагавшийся В.В. Субботиным с коллегами [2]. Кроме этого, было установлено два новых для рифа МПМ - паларстанид и стибиопалладинит, причем последний - впервые для ФПРК. Неизвестная ранее минеральная фаза состава $(\mathrm{Pd}, \mathrm{Ag})_{2}(\mathrm{Te}, \mathrm{Sn})$, наблюдаемая в ассоциации с паларстанидом, является, по-видимому, первой находкой в мире.

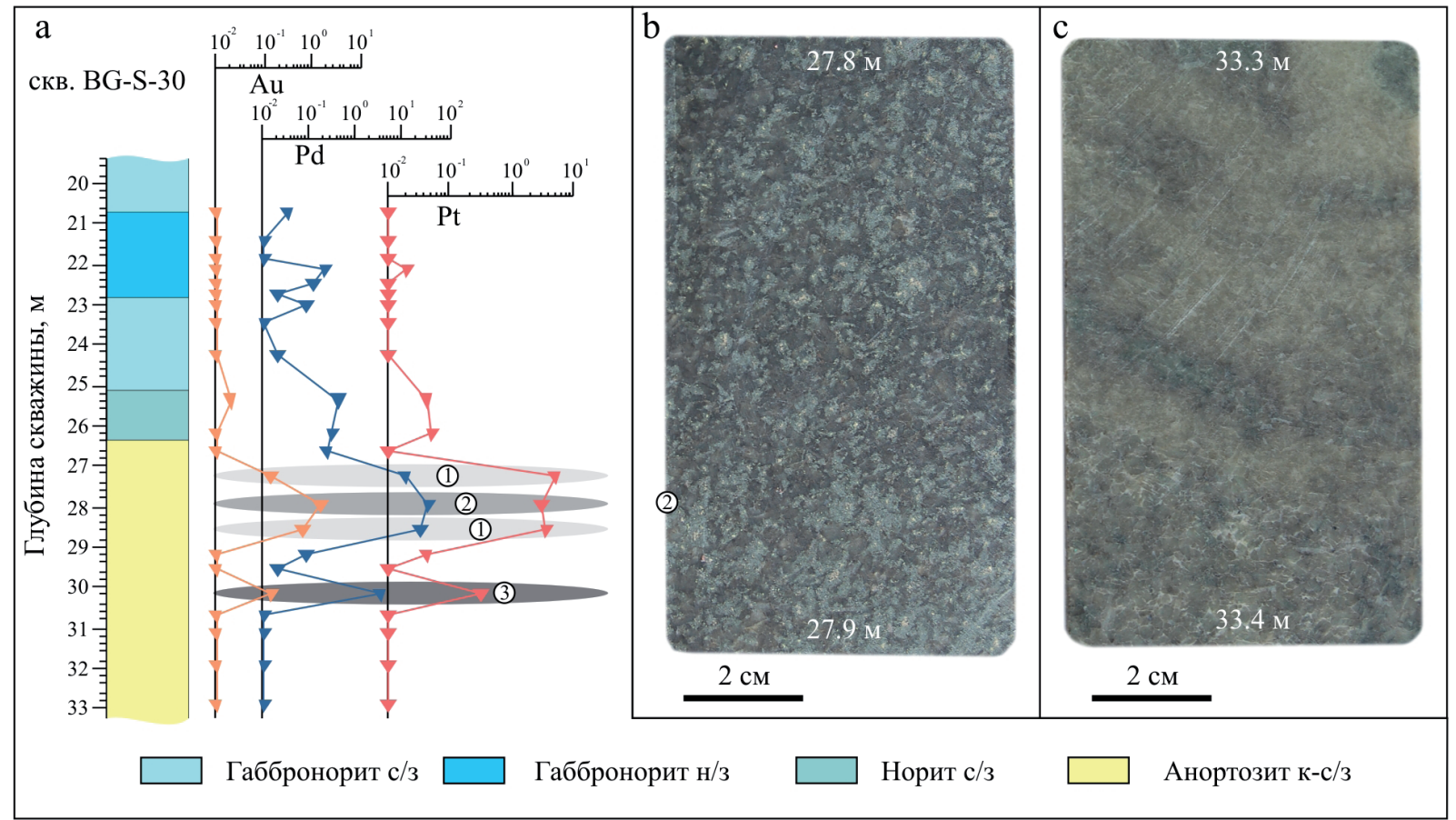

Рис. 1. а - Фрагмент геологической колонки скважины BG-S-30, пересекшей Южный риф на участке Южный Каменник, с вариациями содержаний $\mathrm{Au}, \mathrm{Pt}, \mathrm{Pd}(\mathrm{ppm}) . \mathrm{b}-\mathrm{c}$ - фотографии спилов образцов керна рудных (b) и безрудных (c) анортозитов. Цифрами показаны условные геохимические типы платинометальной минерализации: 1-ый тип $(\mathrm{Pd} / \mathrm{Pt}=2-6)$ представлен аншлифами 27.5, 27.55; 2-ой тип $(\mathrm{Pd} / \mathrm{Pt}>10)-27.8,27.9,28.15$, $28.15(2)$; 3-ий тип $(\mathrm{Pd} / \mathrm{Pt}=6-10)$ - 30.0, 30.2. Сокращения: с/3 - среднезернистый, н/3 - неравномернозернистый, к-с/з - крупно-среднезернистый. 


\section{Методы исследования}

ЭПГ и золото определены в керновых пробах (рис. 1, а) методом атомно-эмиссионной спектрометрии с индуктивно-связанной плазмой после пробирной плавки проб в лаборатории «Стюарт Геокемикл энд Эссей» (г. Москва). Три типа платинометального оруденения Южного рифа (рис. 1, а), выделенные в разрезе условно по геохимическим признакам, исследованы в 8 аншлифах. Использованные для сравнения рудные анортозиты J-М рифа (Стиллуотер, США), изучены в образце СТ-1-15, который был предоставлен В.П. Павловым. Минеральный состав исследовался в РЦ «Геомодель» (г. Санкт-Петербург, аналитик В.В. Шиловских) на сканирующем электронном микроскопе Hitachi S-3400N с использованием энерго-дисперсионного спектрометра (EDX) Oxford $\mathrm{X}-\mathrm{Max} 20$ при следующих установках: ускоряющее напряжение $20 \mathrm{\kappa B}$, ток зонда 1,5нА, экспозиция 30 секунд на спектр, оптимизация зонда перед измерениями проводилась на металлическом кобальте, калибровка спектрометра осуществлялась с использованием стандартных образцов природных и синтетических соединений.

\section{Результаты исследований и обсуждение}

Южный риф представлен сульфидной вкрапленностью (1-5 об. \%; рис. $1, \mathrm{~b})$ в верхней части 10-15-метрового пласта анортозитов (рис. 1, с) в Верхнем расслоенном горизонте Западно-Панского массива. Во вкрапленности присутствуют халькопирит, пентландит, пирротин, пирит, сфалерит, реже миллерит, Ag- и Pd-пентландит. Минерализованные анортозиты, как и в J-M рифе комплекса Стиллуотер, содержат до нескольких десятков ppm ЭПГ и Аu. Отличительной особенностью Южного рифа является прерывистость сульфидной вкрапленности по простиранию и падению анортозитов. Оруденение прослеживается на первые десятки метров и выклинивается, затем появляется вновь в кровле анортозитов. Появление и резкое выклинивание оруденения происходит на протяжении более 15 км простирания пласта. Кроме этого, рифы отличаются друг от друга по морфологии сульфидов (рис. 2, a-b). В Южном рифе сульфиды слагают эмульсионную вкрапленность (рис. $1, b)$ с единичными более крупными гнездами в агрегате минералов группы эпидота, которые замещают как минералы интерстиций, так и частично кумулусный плагиоклаз (рис. 2, b). В анортозитах J-M рифа процессы замещения проявлены в значительно меньшей степени - сульфиды образуют интерстициальные гнезда с тонкой каймой эпидота между зернами плагиоклаза (рис. 2, a). Макроскопически минерализованные анортозиты комплекса Стиллуотер близки к безрудным анортозитам, встреченным нами в скважине (рис. 1, с).

Вариации концентраций ЭПГ по разрезу скважины (рис. 1, а) позволяют условно выделить три типа оруденения в Южном рифе по геохимическим признакам. Тип 1 и 2 представляют наиболее богатое оруденение и различаются по отношению $\mathrm{Pd} / \mathrm{Pt}-2-6$ и $>10$ соответственно. Тип 3 отделен в разрезе от предыдущих прослоем безрудных анортозитов и имеет промежуточное отношение $\mathrm{Pd} / \mathrm{Pt}(6-10)$.

Данные о МПМ в каждом из типов суммированы в табл. 1. Всего в скважине был установлен 21 минеральный вид и одна минеральная фаза ЭПГ и Аu. МПМ находятся в эпидоте, в срастаниях и в виде включений в Fe-Ni-Cu сульфидах. Размер большинства встреченных МПМ сравнительно крупный (15-25 мкм). В некоторых случаях это метасомы размером до 300 мкм.

Tun 1 представлен минеральными видами относящимися к элементам, сульфидам (рис. 2, d), теллуридам, арсенидам и теллуроарсенидам, а так же к сульфоарсенидам. С точки зрения преобладающей минеральной ассоциации первый тип является сульфидным, поскольку основным минералом здесь является высоцкит. Этот тип наименее представителен по разнообразию МПМ.

Наибольшим минеральным разнообразием характеризуется тип 2, в котором широко представлены сульфиды, теллуриды (рис. 2, е), арсениды (рис. 2, f) и арсенотеллуриды (табл. 1). По набору основных и часто встречающихся минералов этот тип можно отнести к арсенидно-сульфиднотеллуридной минеральной ассоциации. В данном типе были выявлены две новые для Южного рифа фазы: паларстанид и минеральная фаза MPh-2. Паларстанид, образующий выделения размером более 5 мкм (рис. 2, g), удовлетворительно рассчитывается на кристаллохимическую формулу 

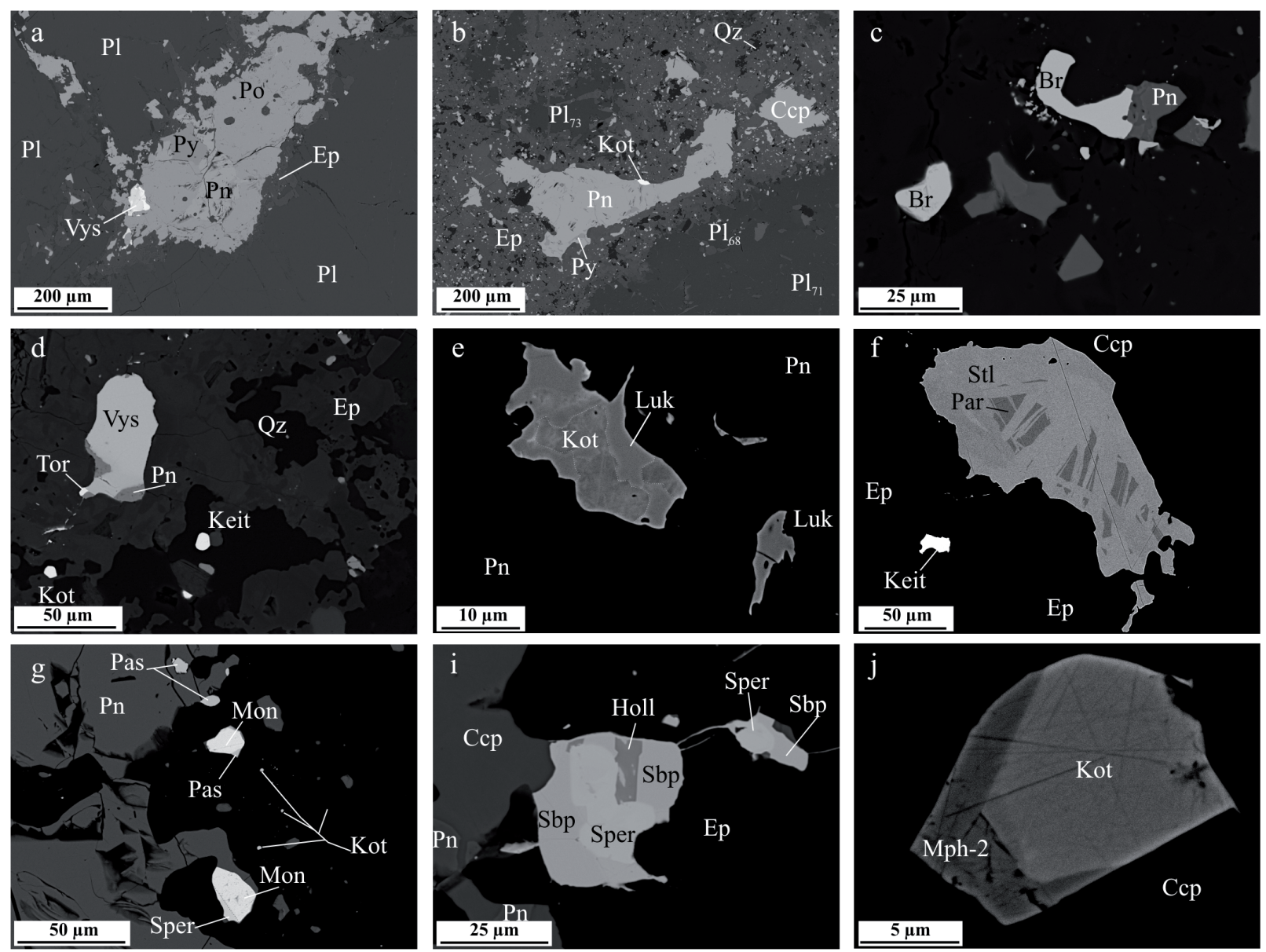

Рис. 2. ВSE изображения МПМ из анортозитов J-М (а) и Южного (b-j) рифов.

Сокращения минералов: $\mathrm{Br}$ - брэггит, Ер - минералы группы эпидота, Hol - холлингуортит, Кeit - кейтконнит, Kot - котульскит, Luk - лукулайсваараит, Mph - минеральная фаза, Mon - мончеит, Par - палладоарсенид, Pas - паларстанид, Pl - плагиоклаз, Pn - пентландит, Рo - пирротин, Рy - пирит, Qz - кварц, Sbp - стибиопалладинит, Sper - сперрилит, Stl - стиллуотерит, Vys - высоцкит.

$\left(\mathrm{Pd}_{4.50-4.76} \mathrm{Fe}_{0-0.18} \mathrm{Ni}_{0-0.16}\right)_{4.75-4.85}\left(\mathrm{Sn}_{0.69-1.53} \mathrm{As}_{0.63-1.42} \mathrm{Hg}_{0.9-0.13}\right)_{2.15-2.25}$ Минерал встречается вместе с мончеитом, котульскитом и сперрилитом. Минеральная фаза MPh-2 имеет состав $\left(\mathrm{Pd}_{1.05-1.19} \mathrm{Ag}_{0.77-1.16} \mathrm{Fe}_{0-0.05}\right)_{2.02-}$ ${ }_{2.21}\left(\mathrm{Te}_{0.40-0.68} \mathrm{Sn}_{0.200 .24} \mathrm{Se}_{0.06-0.18} \mathrm{Au}_{0.10}\right)_{0.79-0.98}$. Выделения Mph-2 были отмечены в краевых частях сульфидных зерен, где они ассоциируют с котульскитом (рис. $2, \mathrm{j}$ ) и серебром.

МПМ из руд типа 3 представлены элементами, сульфидами (рис. 2, с), теллуридами, арсенидами и отсутствующими в других типах минералами системы Pd-As-Sb (табл. 1). По основным и часто встречающимся МПМ минеральную ассоциацию можно отнести к антимонидно-арсениднотеллуридной. К минералам системы Pd-As-Sb, выделяющим этот тип среди прочих, относятся мертиит и стибиопалладинит; последний ранее в ФПРК не отмечался. Стибиопаладинит образует выделения размером более 20 мкм. Он обнаружен в сростке со сперрилитом и холлингуортитом на границе халькопирита и эпидота (рис. 2, i). Составы стибиопалладинита удовлетворительно рассчитываются на кристаллохимическую формулу $\left(\mathrm{Pd}_{4.88-5.03} \mathrm{Fe}_{0-0.10} \mathrm{Ni}_{0-0.05}\right)_{5.01-5.06}\left(\mathrm{Sb}_{1.49-1.99} \mathrm{As}_{\text {0-0.46 }}\right)_{1.94-1.99}$.

Таким образом, изучение минерального состава трех геохимических типов оруденения Южного рифа позволяет различать в разрезе сульфидную, арсенидно-сульфидно-теллуридную и антимонидно-арсенидно-теллуридную минеральные ассоциации МПМ. В Ј-М рифе при умеренном отношении $\mathrm{Pd} / \mathrm{Pt}(\sim 4)$ [3] преобладает сульфидная ассоциация МПМ (табл. 1), как и в наиболее высокоплатиновом оруденении Южного рифа. Отметим, что для понимания генетического значения той или иной ассоциации МПМ и ее связи с геохимией руд требуются дальнейшие детальные исследования других пересечений рифа, однако уже сейчас полученные данные показывают высокие 
перспективы изучения разрезов рудных зон ФПРК с точки зрения обнаружения новых минералов.

Таблица 1. МПМ и Аu из разреза Южного рифа по скважине BG-S-30 в сравнении с минералами из анортозитов рифа Ј-М (аншлиф СТ-1-15).

\begin{tabular}{|c|c|c|c|c|c|}
\hline Минерал & Формула & Тип 1 & Тип 2 & Тип 3 & $\mathrm{~J}-\mathrm{M}$ \\
\hline \multicolumn{6}{|l|}{ Элементы } \\
\hline Золото & $\mathrm{Au}$ & $\bullet$ & $\bullet \bullet$ & • & $\bullet$ \\
\hline Палладий & $\mathrm{Pd}$ & $\bullet$ & & & \\
\hline Серебро & $\mathrm{Ag}$ & & & $\bullet$ & \\
\hline \multicolumn{6}{|c|}{ Сульфиды $P d-P t$} \\
\hline Высоцкит & $(\mathrm{Pd}, \mathrm{Pt}, \mathrm{Ni}) \mathrm{S}$ & 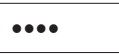 & $\bullet$ & • & $\bullet \bullet$ \\
\hline Брэггит & $(\mathrm{Pt}, \mathrm{Pd}, \mathrm{Ni}) \mathrm{S}$ & $\bullet$ & $\bullet$ & $\bullet$ & $\bullet$ \\
\hline Лафламмеит & $\mathrm{Pd}_{3} \mathrm{~Pb}_{2} \mathrm{~S}_{2}$ & & - & & \\
\hline \multicolumn{6}{|c|}{ Теллуриды $P d-P t$} \\
\hline Кейтконнит & $\mathrm{Pd}_{20} \mathrm{Te}_{7}$ & $\bullet$ & $\bullet$ & & \\
\hline Теларгпалит & $(\mathrm{Pd}, \mathrm{Ag})_{3} \mathrm{Te}$ & - & $\bullet \bullet$ & $\bullet$ & \\
\hline Котульскит & $\mathrm{Pd}(\mathrm{Te}, \mathrm{Bi})$ & $\bullet$ & $\bullet \bullet \bullet$ & $\bullet \bullet$ & .•• \\
\hline Мончеит & $\mathrm{Pt}(\mathrm{Te}, \mathrm{Bi})_{2}$ & & $\bullet$ & $\bullet$ & $\bullet$ \\
\hline Луккулайсваараит & $\mathrm{Pd}_{14} \mathrm{Ag}_{2} \mathrm{Te}_{9}$ & & $\bullet$ & & \\
\hline Сопчеит & $\mathrm{Ag}_{4} \mathrm{Pd}_{3} \mathrm{Te}_{4}$ & & $\bullet$ & & \\
\hline \multicolumn{6}{|c|}{ Арсениды-теллуроарсениды Pd-Pt } \\
\hline Сперрилит & $\mathrm{PtAs}_{2}$ & $\bullet$ & $\bullet \bullet$ & $\bullet \bullet$ & $\bullet$ \\
\hline Стиллуотерит & $\mathrm{Pd}_{8} \mathrm{As}_{3}$ & $\bullet$ & $\bullet$ & & \\
\hline Торнроозит & $\mathrm{Pd}_{11} \mathrm{As}_{2} \mathrm{Te}_{2}$ & - & $\bullet \bullet$ & - & \\
\hline Палладоарсенид & $\mathrm{Pd}_{2} \mathrm{As}$ & & $\bullet$ & - & \\
\hline \multicolumn{6}{|c|}{ Сульфоарсениды ЭПГ } \\
\hline Холлингуортит & RhAsS & & & ..• & \\
\hline Ирарсит & (Ir,Os, Ru, Rh,Pt)AsS & $\bullet$ & & & \\
\hline \multicolumn{6}{|c|}{ Интерметаллидьь-антимониды $P d$} \\
\hline Паоловит & $\mathrm{Pd}_{2} \mathrm{Sn}$ & & & & $\bullet$ \\
\hline Паларстанид* & $\mathrm{Pd}_{5}(\mathrm{Sn}, \mathrm{As})_{2}$ & & $\bullet$ & & \\
\hline Стибиопалладинит** & $\mathrm{Pd}_{5} \mathrm{Sb}_{2}$ & & & $\bullet$ & \\
\hline Мертиит & $\mathrm{Pd}_{11}(\mathrm{Sb}, \mathrm{As})_{4}$ & & & $\cdot$ & $\bullet$ \\
\hline Мертиит-II & $(\mathrm{Pd})_{8}(\mathrm{Sb}, \mathrm{As})_{3}$ & & & & $\bullet$ \\
\hline \multicolumn{6}{|c|}{ Минеральные фазы } \\
\hline MPh-1 & $\mathrm{Pd}_{2} \mathrm{Te}$ & & & & $\bullet$ \\
\hline $\mathrm{MPh}-2 * * *$ & $(\mathrm{Pd}, \mathrm{Ag})_{2}(\mathrm{Te}, \mathrm{Sn})$ & & - & - & \\
\hline
\end{tabular}

Примечание: •- единичные зерна, $\bullet-$ - редкий, $\bullet \bullet-$ часто встречающийся, $\bullet \bullet \bullet-$ основной минерал; новые находки: * - для Южного рифа, ** - для ФПРК, *** - в мире.

Работа выполнена в рамках темы НИР №0231-2015-0002 и частично поддержана из средств РФФИ (16-05-00367, 15-35-20501).

\section{Литература}

1. Грошев Н.Ю., Борисенко Е.С., Савченко Е.Э. Состав плагиоклаза в разрезе главного анортозитового пласта Западно-Панского платиноносного массива (Кольский полуостров, Россия): новые данные // Вестник КНЦ. 2017. № 1. С. 5-15.

2. Субботин В.В., Корчагин А.У., Савченко Е.Э. Платинометалльная минерализация Федорово-Панского рудного узла: типы оруденения, минеральный состав, особенности генезиса // Вестник Кольского научного центра РАН. 2012. №. 1. С. 55-66.

3. Todd S.G., Keith D.W., Le Roy L.W., Schissel D.J., Mann E.L., Irvine T.N. The JM platinum-palladium reef of the Stillwater Complex, Montana; I, Stratigraphy and petrology // Econ. Geol. 1982. 77(6). P. 1454-1480. 